\title{
Progress in Research and Application of Natural Polymer Coagulants
}

\author{
Xiao $\mathrm{Yu}^{1}$ and Ying $\mathrm{Fu}^{1, *}$ \\ ${ }^{1}$ School of Civil Engineering and Architecture, University of Jinan, Jinan 250022, China
}

\begin{abstract}
In recent years, natural polymer coagulant has become a hot spot in the field of coagulants due to its safety, harmlessness and biodegradability. This paper introduced the status quo of research of natural polymer coagulants such as starch, chitosan, cellulose and lignin coagulants. And some hot applications in water treatment were discussed, such as heavy metal wastewater, dye wastewater, microalgae collection and sludge dewatering. Finally, the development trend of natural polymer coagulants was prospected.
\end{abstract}

\section{Introduction}

In recent years, with the intensification of water pollution and increasing water supply problems, Chinese researchers have done a lot of research and analysis on water treatment. And the coagulation process has become one of the indispensable links in water treatment due to its simple operation and cost-effectiveness [1]. Proper selection and use of high-performance coagulants is a key issue in water treatment [2]. There are many types of coagulants currently studied, but two types are widely used. One type is an inorganic coagulant represented by iron and aluminum, which is relatively cheap, but it has the problems of being greatly affected by $\mathrm{pH}$, prone to produce a large amount of activated sludge, and residual metal ions in water [3]. The other is a synthetic organic coagulant represented by polyacrylamide, which makes up for the shortcomings of inorganic coagulants in many aspects. At the same time, its dosage is small and efficient, but its residual monomers have certain toxicity and are easy to cause harm to human body [4]. Because the above inorganic coagulants and synthetic organic coagulants have the danger of secondary pollution, the research of economic, environmental protection, safe and efficient coagulants are of great significance to environmental protection and human development.

Natural polymer coagulant has gradually become a hot spot in the field of coagulants due to its advantages such as multiple active groups, diverse structures, rich sources, safety and non-toxicity, and biodegradability [5], which is a green coagulation in line with future developmen. This article reviewed the research status and application hotspots of natural polymer coagulants in recent years.

\section{Research Status of Natural Polymer Coagulants}

Natural polymer coagulant refers to a product made by extracting or modifying organic polymer substances in agricultural and sideline products in nature [6]. At present, the four types of starch, chitosan, cellulose and lignin have become hot spots for the development of natural polymer coagulants at home and abroad.

\subsection{Starch}

Starch is one of the first natural polymer coagulants to be developed. It is rich in resources, highly regenerative, and water-soluble. Starch can be modified by reactions such as esterification, etherification, oxidation, and crosslinking of these hydroxyl groups, so that the copolymer has the advantages of both natural polymers and synthetic polymers [7]. Modified starch flocculants can be divided into non-ionic starch coagulants, cationic starch coagulants, anionic starch coagulants and amphoteric starch coagulants according to the charging properties of their hydrophilic base ions [8]. Yusoff et al. [9] modified the durian seed starch into a starch coagulant by physicochemical modification, and studied the treatment effect of landfill leachate by combining it with polyaluminum chloride (PAC). The results showed that the combined effect was better, and the color, turbidity, COD, and SS were further reduced, and the dosage of PAC was greatly reduced. Huang et al. [10] prepared a starch-graft-poly(2-methacryloxyethyl) trimethyl ammonium chloride (St-g-PDMC) coagulant, and examined its effect on kaolin and E. coli suspensions as well as their mixtures. The results showed that St-gPDMC had very good flocculating ability and antibacterial performance. It can reduce the dosage of coagulant and disinfectant to a certain extent when it is used in water supply plants.

\subsection{Chitosan}

\footnotetext{
* Corresponding author: cea_fuy@ujn.edu.cn
} 
Chitosan is a polymer material obtained by removing acetamide groups from chitin, which integrates bridging and net capture functions, and can show good adsorption capacity for pollutants [11]. The free amino group on the chitosan molecular chain can be protonated in an acidic medium, which makes it exhibit cationic polyelectrolyte characteristics and can effectively improve the removal effect of pollutants in water [12]. It is worth pointing out that chitosan has poor solubility in neutral and alkaline water environments, which greatly limits the application of chitosan. However, based on the amino and carboxyl groups on the chitosan molecular chain, chemical groups can be introduced through modification methods to effectively improve the physicochemical properties of chitosan, improve water solubility, charge density, relative molecular weight, and further expand the application range [13]. Common chemical modification methods include etherification, acylation, alkylation, polymer graft copolymerization and magnetization modification [14], etc. Liu Zhifeng [15] prepared sulfonated chitosan using natural polymer chitosan as raw material and concentrated sulfuric acid as sulfonating reagent, and used it in the treatment of coking wastewater. The results showed that the removal rates of $\mathrm{COD}_{\mathrm{Cr}}$, ammonia nitrogen and chroma in coking wastewater were $65.0 \%, 69.0 \%$ and $74.0 \%$, respectively, achieving good coagulation effect. Lu et al. [16] grafted maleyl chitosan and polyacrylamide with ultraviolet light to prepare a new type of chitosan coagulant, and investigated its flocculation performance on algaecontaining wastewater. The results showed that its flocculation performance was better than that of polyacrylamide, polyaluminum, and polyferric sulfate.

\subsection{Cellulose}

Cellulose exists widely in human living space and various fields. It is the natural polymer material with the largest reserves in nature. And it has always been a research hotspot in the development and utilization of natural polymer coagulants [17]. Among them, modified cellulose coagulants are currently the most studied. Ramzi Khiari [18] used different types of sodium hydroxymethyl cellulose in date palm leaf axis for drinking water treatment. It was found that it is an ecofriendly flocculant and the turbidity removal rate can reach $95.0 \%$, compared with commercial anionic polyacrylamide, the flocculation effect obtained by treating wastewater with the same pollution load is better. Zhu et al. [19] synthesized a natural dicarboxyl cellulose flocculant in one step by the Schiff base method, and studied its flocculation performance on kaolin suspension and paper mill effluent. The results showed that the flocculant had better removal ability and stability than polyacrylamide and polyaluminum chloride.

\subsection{Lignin}

Lignin is an aromatic polymer that exists in plant fibers. It has flocculating properties because it contains functional groups such as hydroxyl, carboxyl, and carbonyl groups. Chemical methods such as condensation and cross-linking reactions cause changes in the molecular weight and configuration of lignin to improve its flocculation performance [20]. At the same time, lignin is the main component of papermaking black liquor. The large amount of papermaking waste liquor discharged not only seriously pollutes the environment, but also causes great waste of material resources. Therefore, the development and utilization of lignin coagulants is of great significance. Ren Shixue [21] synthesized a trimethy quaternary ammonium salt of wheat-alkali-lignin under microwave irradiation using wheat straw alkali lignin extracted from papermaking black liquor as the raw material, and tested its flocculation performance. The results showed that the flocculant had a decolorizing effect on the acid dyes of Acid Red B and Acid Orange GG, and had sedimentation of flocculation on kaolin suspensions. Yuan Junyi et al. [22] used acrylamide, dimethyl diallyl ammonium chloride and lignin sulfonate as raw materials to synthesize a ternary copolymer lignin sulfonate amphoteric coagulant by inverse emulsion polymerization. The coagulant had a removal rate of more than $80 \%$ of COD in wastewater such as papermaking black liquor, printing and dyeing wastewater, and landfill leachate.

\section{Application hot spots of natural polymer coagulants}

The main goal of traditional coagulants is to remove colloidal substances and suspended particles formed by insoluble substances in water. For natural polymer coagulants, it has shown good application prospects in heavy metal wastewater, dye wastewater, microalgae collection and sludge dewatering, and has gradually become a hot spot in its application at home and abroad.

\subsection{Treatment of heavy metal wastewater}

With the continuous development of China's industry, the discharge of heavy metal wastewater is also increasing. Heavy metal pollutants usually have acute or chronic toxicity and can't disappear through selfpurification, but can be enriched through the biological food chain, posing a huge threat to human health and environmental safety [23]. Natural polymer coagulants have surface active groups with large molecular structure, which can use chelation and adsorption to remove heavy metals [24]. Modification of such polymer materials through derivatization reactions such as methylolation, acylation, and carboxylation can significantly improve their removal effect on heavy metals [25]. You et al. [26] prepared a copolymer flocculant derived from starch and chitosan, and also used it as an environmentally friendly adsorbent, with a removal rate of $\mathrm{Cr}^{6+}$ in aqueous solutions up to $90 \%$. Lin Meiying et al. [27] prepared amino modified starch AMS by emulsion polymerization. For actual electroplating wastewater, AMS had a removal rate of $\mathrm{Cu}^{2+}, \mathrm{Cr}^{6+}, \mathrm{Zn}^{2+}$ close to $100 \%$, and the regeneration was good. 


\subsection{Treatment of dye wastewater}

Dyes are common water pollutants in the textile, leather, paper, and dye manufacturing industries. Most of them are organic and contain chromophores, which make the water quality of dye wastewater change to a large extent [28]. Colored dye wastewater is not only highly toxic to aquatic organisms, but also can interfere with natural balance and affect the symbiotic relationship of organisms by reducing the light and activity of aquatic organisms [13]. Therefore, the effective treatment of dye wastewater is very important. Coagulation precipitation method is one of the effective methods for the treatment of dye wastewater, but traditional inorganic coagulants are not efficient in removing dyes and are easily affected by $\mathrm{pH}$ changes. Many new natural polymer coagulants are improved to solve these problems and achieved some good results. Qiu Yexian et al. [29] prepared a cationic corn starch flocculant with 2, 3-epoxypropyl trimethyl ammonium chloride as the etherifying agent and isopropanol as the dispersant without adding any catalyst. And the decolorization rate of printing and dyeing wastewater up to $97.1 \%$. XU et al. [30]demonstrated the removal of methylene blue by poly (2-acrylamide-2methyl propane sulfonic acid) grafted magnetic chitosan, which proved that the rich $-\mathrm{SO}_{3} \mathrm{H}$ can promote the electrostatic attraction of methylene blue cations.

\subsection{Sludge dewatering}

Sludge is an inevitable product in the process of sewage treatment. With the improvement of people's living standards and rapid industrial development, sludge production has increased year by year [31-32]. The water content of sludge is usually as high as $95.0 \%$. Higher water content will require a lot of storage space, resulting in waste of resources. At the same time, sludge often contains heavy metals, refractory organic matter, and a small amount of pathogenic microorganisms and parasites, which are harmful to the environment [33]. Therefore, the dehydration conditioning of sludge becomes particularly important and essential. In recent years, the research on the application of natural polymer coagulants as sludge conditioners has become more and more intensive, and has shown good application prospects in terms of sludge dewatering. Because peanut shell contains a lot of cellulose and lignin, Qiu Huidong et al. [34] prepared a cationic flocculant (PNEA) using peanut shell as raw material and 2,3-epoxypro pyltrimethyl ammonium chloride as an etherifying agent. The dewatering rate of sewage treatment plant sludge by PNEA was $89.0 \%$, and the clear liquid permeability was $93.5 \%$. Sujit Banerjee [35] modified soybean protein as a flocculant for the treatment of papermaking sludge, the results showed that it had good sludge dewatering performance, and the maximum solid content of the filter cake after dehydration reached $36 \%$.

\subsection{Microalgae collection}

Microalgae is an autotrophic plant with great application prospects, which can be used as biomass fuel, environmental monitoring tools, animal feed, etc. [36]. However, the collection of microalgae is one of the main limiting factors for the utilization of microalgae. However, the collection of microalgae is one of the main limiting factors for the use of microalgae. At present, the commonly used collection methods include centrifugation, filtration, air flotation, coagulation and sedimentation [37]. Among them, the coagulation sedimentation method is considered to be one of the most effective methods for large-scale collection of microalgae. Because inorganic coagulants are difficult to meet the requirements of algae collection, there are problems of secondary pollution and affecting subsequent processing [38]. Therefore, many researchers began to use natural polymer coagulants for the collection of microalgae. Dong Lei et al. [39] modified the activated fly ash filtrate with chitosan and used it to perform flocculation experiments on algae in different areas of Lake Tai. The results showed that for the water pumped, the removal rate was up to $89.6 \%$ when the dosage was $0.7 \mathrm{mg} / \mathrm{L}$. For the high concentration algae water on the shore, the algae removal rate can reach $85.77 \%$ within half an hour when the dosage was $4 \mathrm{mg} / \mathrm{L}$. Choy et al. [40] compared the ability of starch flocculants and chemical flocculants to collect chlorella, and the results showed that the collection rates of alum and polyaluminum chloride on chlorella were about $36.6 \%$ and $40 \%$. The autoclaved rice starch flocculant collection rate of coccus can reach $80 \%$, which is equivalent to twice that of chemical flocculants.

\section{Conclusion and Outlook}

With the increasing problem of water pollution and the increase of people's environmental requirements, research on safe and efficient coagulants in coagulation processes is imperative. Among them, natural polymer coagulant, as a representative of green coagulant, has become a research hotspot in the field of coagulants with its unique advantages. From the above review, it can be seen that the single use of natural starch, chitosan, cellulose and lignin coagulants have not been able to meet people's production needs, and more and more natural polymer modified coagulant products have appeared in people's field of vision, good results have been achieved in water treatment and sludge dewatering. However, most of the research on natural polymer coagulants are still in the pilot stage of the laboratory. Therefore, it is the focus of future research to develop cheaper and more efficient coagulants and transform the results into practical industrial applications in time.

\section{References}

1. K. Xu, H.W. Wang, X.C. Liang, et al. J. Polym. Environ. 26, 71, 2782-2792 (2018)

2. X.Q. Chen, C.L. Si, P. Fatehi, Carbohydr. Polym. 186, 358-366 (2018) 
3. Y.M. Li , S.L. YU, Y.L. TANG, Technology of Water Treatment, 37, 9, 11-14 (2011)

4. Q.Y. ZHOU, W. GUO, Y.XIAO, et al. Guangzhou Chem. Indy. 2013, 41, 7, 50-52. (2013).

5. S, Krishnamoorthi, R. Singh, J. PSynthesis, Appl Polym. Sci. 101, 5, 2109-2122 (2006)

6. N. LU, University of Jinan, Jinan, China (2017)

7. W. Liu, J.J. Ma, Xinding. Y, et al. Environ Protec Chem Ind. 38, 2, 141-147 (2018)

8. X.L. YANG, [J]. Chem Adh, 41, 1, 68-71 (2019)

9. M.S. Yusoff, H.A. Aziz, M.F.M.A. Zamri, et al. Waste Manage. 74, 362-372 (2018)

10. M. Huang, Z.Z. Liu, A.M. Li, et al. J. Environ Manage. 196, 63-71 (2017)

11. P. Hassanzadeh, M. Moradi, N. Vaezi, et al. Vet Res Forum, 9, 1, 73-79 (2018).

12. H. Liu, Wuhan University, Wuhan, China (2004)

13. H.L. ZHENG, X. Chen, W.X. Huang, et al. Technology of Water Treatment, 45, 11, 1-6 (2019)

14. Y,B, Feng, S.M. Lu, Chinese Journal of Chemical Enterprise Managenment, 14 ,22-23. (2019)

15. Z.F. Liu, China Hangzhou Chemical Industry, 43, 4, 22-24 (2012)

16. X. Lu, Y.H Xu, W.Q. Sun, et al. Sci. Total. Environ. 609, 410-418 (2017)

17. X.X. Cao, J.G. Xiong. S.M. Chen, et al. Journal Chongqing Technology and Business University (Natural Sci. Ed) 28, 6, 635-638 (2011)

18. K. Ramzi , D.D. Sonia, A. Chadlia, et al. J. Environ Sci-China, 22, 10, 1539-1543 (2010)

19. H.C. Zhu, Y. Zhang, X.G. Yang, et al. J. Hazard. Mater. 296, 1-8 (2015)

20. X. CHEN, Chem. Engineering \& Equipment, 6, 214-215 (2018)

21. S.X. REN, G.Z. FANG, Y.L. MA, J. Beijing. Fore Univ, 2012, 34, 6, 137-142 (2012)

22. J.Y. YUAN, Y.C. ZHANG, P. YIN, Applied Chemical Industry. 46, 8, 1051-1054.(2017)

23. F.L. DU, M. XU, G. WANG, et al. Industrial Water Treatment, 34, 12, 12-16 (2014)

24. P. Kanmani, J. Aravind, M. Kamaraj, et al. Bioresource Technol. 242, 295-303 (2017)

25. S.C ZHU, Y.J SUN, W.Q SUN, et al. Chinese Journal of Water Purification Technology, 37, 11, 40-50 (2018)

26. L.J You, L.D Song, F.F Lu, et al. Polym. Eng. Sci. 56 , 11 , 1213-1220 (2016)

27. M.Y LIN , X.Q. SHANG, S.Y. LI, et al. Chem. Ind. Eng. Prog. 30, 4, 854-856 (2011)

28. J.Y. SUI, Chinese Journal of Textile Auxiliaries, 35, 1, 16-21 (2018)

29. Y.X. QIU, Y.X ZHU, X.F. DING, Journal of Suzhou University of Science and Technology (Nat. Sci. Ed.), 28, 3, 45-49 (2011)
30. B. XU, H. ZHENG, Y. WANG, et al., Int. J. Biol. Macromol. 112, 648-655 (2018)

31. X.L. WANG, Z.Z. ZENG, H.C. WANG, et al. Chinese Journal of Environmental Engineering, 32, 3, 150-154 (2014)

32. J.Z. CHEN, G.Y HUANG. China Resources Comprehensive Utilization, 34, 6, 35-38 (2016)

33. W.J. YAN, Y.J. SUN, L.Y. FENG, et al. Journal of Civil, Architectural \& Environmental Engineering,

37, S1, 41-45 (2015)

34. H.D. QIU, L.P. ZHU, G.B. LUO, et al. Journal of Petrochemical Universities, 21, 4 ,30-33 (2001)

35. S. Banerjee, Process Biochem. 49, 120-123 (2014)

36. Z.J. WANG, Z. WANG, K. XU, et al. Chinese Journal of Applied Chemical Industry, 48, 3, 646650 (2019)

37. F. Roselet, D. Vandamme, M. Roselet. et al. Bioenerg Res. 10, 2, 427-437 (2017)

38. J.Q ZHANG, N. PANG, S.Q. YANG, et al. Chinese Journal of Environmental Protection and Circular Economy, 37, 3, 5-30 (2017)

39. L. DONG, J.L. QIAO, P. ZHANG et al. Chinese Journal of Environmental Engineering, 29, 5, 48-51 (2011)

40. S.Y. Choy, K.M.N. Prasad, T.Y. Wu, et al. Algal Res. 29, 343-353 (2018) 